\title{
VERSATIL TOOLS: DIGITAL SURVEY AND VIRTUAL REALITY FOR DOCUMENTATION, ANALYSIS AND FRUITION OF CULTURAL HERITAGE IN SEISMIC AREAS
}

\author{
I. Trizio ${ }^{1,}$, , F. Savini ${ }^{2}$, A. Giannangeli ${ }^{1}$, S. Fiore ${ }^{3}$, A. Marra ${ }^{1}$, G. Fabbrocino ${ }^{1,4}$, A. Ruggieri ${ }^{4}$ \\ ${ }^{1}$ ITC-CNR, Institute for Construction Technologies, Italian National Research Council, 67100 L'Aquila, Italy- (ilaria.trizio, \\ Giannangeli, marra, Fabbrocino)@itc.cnr.it \\ ${ }^{2}$ Independent researcher, 67100 L'Aquila, Italy - fransav83@gmail.com \\ ${ }^{3}$ CNR Press Office, Italian National Research Council, 00185 Rome, Italy - sandra.fiore@cnr.it \\ ${ }^{4}$ Department of Biosciences and Territory, University of Molise, 86100 Campobasso, Italy - (giovanni.fabbrocino@unimol.it, \\ a.ruggieri3@studenti.unimol.it)
}

\section{Commission II}

KEY WORDS: Digital Survey, Virtual Reality, Documentation of Cultural Heritage, Architectural Survey, Diagnostics of the Cultural Heritage, Conservation

\begin{abstract}
:
The paper deals with an interdisciplinary research activity aiming at developing a digital and integrated tool able to collect several data concerning the cultural heritage, and to manage and communicate them to a wide community. The small church of San Menna, located in the hamlet with same name in the municipality of Lucoli not so far from L'Aquila city, was the object of the research. The church has been chosen for its historical significance, its architectural peculiarity and for the valuable artworks that it preserves.

Based on a photogrammetric model of the church, also used for the remote analysis of cultural asset (planimetric and evolutionary hypotheses, three-dimensional stratigraphic analysis, etc.) a virtual word usable in Virtual Reality (VR) has been developed. The VR setting allows the accessibility of a digital semantic model with information that can be activated with special interactive hotspots (images, texts and audio), which are able to provide an immersive and all-encompassing experience to the tourist. The potentialities of the same tool in the context of diagnosis and conservation process related to cultural heritage in seismic areas, such as those of the Abruzzi Apennines, have also been investigated through the integration of forms concerning the significant features of the artistic assets surveyed in the construction.
\end{abstract}

\section{INTRODUCTION}

\subsection{D modelling and cultural heritage}

The field of cultural heritage has been strongly renewed due to the use of recent and new digital technologies. These have indeed modified the way to approach the knowledge, fruition and enhancement of the historical and built heritage.

The use of digital technologies, including those of Information and Communication Technology (ICT), in the field of cultural heritage has allowed the development of highly detailed threedimensional digital models, which support the enhancement of the heritage thanks to the possibilities provided by several software of virtual reality that allow the remote use of the assets located on a territory. At the same time, the implementation and fruition of digital models enhance the dissemination of knowledge acquired, also in the context of multidisciplinary researches, to a wider community characterized not only by researchers and academics of several disciplines but also by not expert people.

Therefore, the use of three dimensional models in the assessment and research of cultural heritage allows to improve the comparison of research results making available a tool that enables the analyses, the management and the development of data collected, also provided by several disciplines involved in the process of knowledge (Marra, 2017).

The field of cultural heritage can benefit from the three dimensional modelling and from ICT use both for educational both for specific and technical purposes. The implementation of digital models that accurately illustrate the cultural heritage, indeed, allow to have digital archives in which qualitative information, concerning the conservation state and the history of an artefact, are combined with quantitative information, related to the geometry of building elements. These correlation between information allows to define: specific and planned analyses, such as the drafting of investigation surveys and the realization of maintenance interventions, promoting the conservation (Marra et al., 2019); new ways to approach culture, making the user no more a simple spectator but a dynamic actor able to interact and interface easily with cultural heritage (MiBAC, 2019; Bettio et al., 2015; Trizio et al., 2019b).

Starting from this awareness, the research group has attempted to combine the issues related to the knowledge and enhancement of cultural heritage though the development of a new digital tool. This has been designed with the aim to include all data collected by several experts involved in order to make them available to a wide community.

The church of San Menna in Lucoli has been identified as application case for its historical and constructive peculiarities, but also for its high cultural value. In the following sections, after a brief description of the study case, the tools and methods applied to develop the research and implement the digital model for Virtual Reality, thanks to low cost and open-source software, are provided.

\subsection{The church of San Menna in Lucoli (L'Aquila)}

The church of San Menna is a small building located in a hamlet of Lucoli municipality. Although currently the territory in which the church is built appears as a neglected mountain area, it was in the past a crossroads of routes to Marsica and Rieti, therefore between Lazio and Umbria, and it belonged to a region rich in economic and cultural trade, related to herding and trade in wool. The church, which was first mentioned in 1215 in a seal issued by Pope Innocent III, has a peculiar configuration that allows to 
understand the many interventions and renovations made over time (fig. 1).

The current inner partition, with two naves, did not correspond to the original project. Indeed, the ancient entrance, today characterized by an eighteenth century portal, is decentralised, displaced on the right and it includes the ancient corner masonry structure that defines the original perimeter of the hall (Placidi 1986; Lico, 2001).

The reconstruction of the building and the extension of left nave could have occurred before the fifteenth century, period to which the valuable frescoes inside the church are dated (fig. 2). Indeed, this building, which appears poor in features, preserves one of the most valuable frescoes of the Abruzzo Renaissance, among

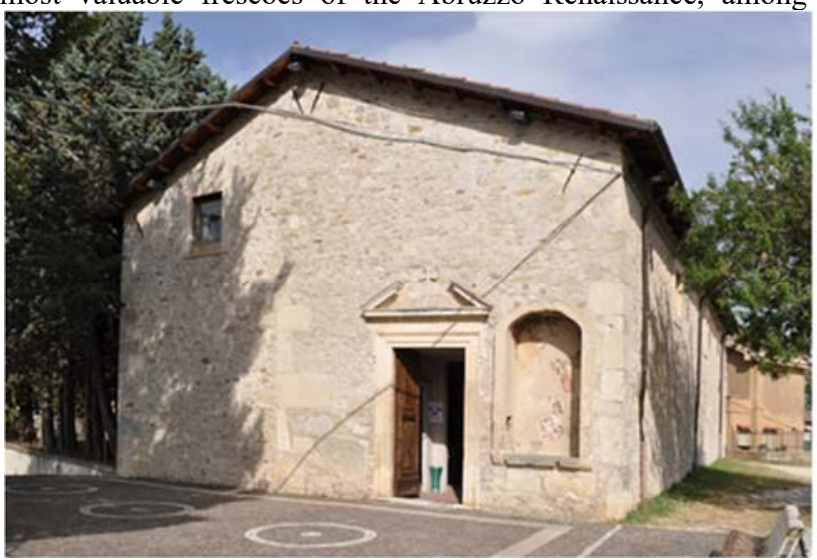

Figure 1. Panoramic views of the church

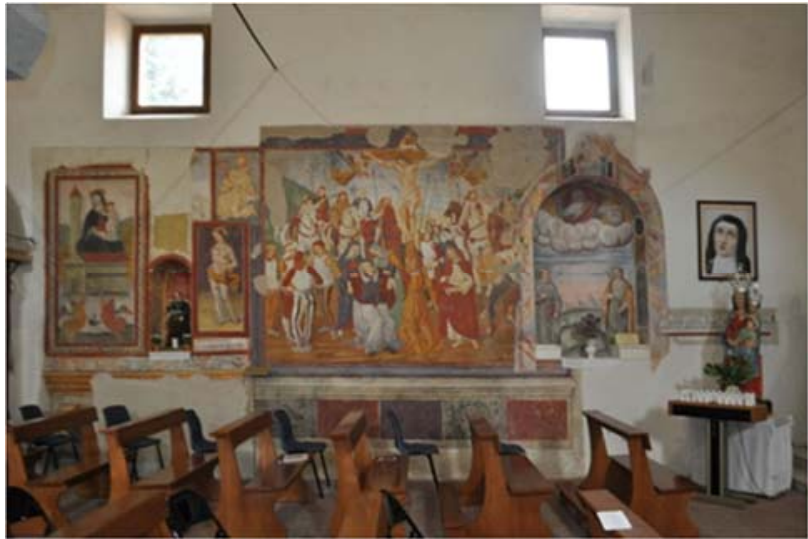

Figure 2. Internal views of the church: on the left, the wall frescoed by Saturnino Gatti and, on the right, the fresco ascribed to Pompeo Cesura

\section{THE APPROACH}

\subsection{Background}

Virtual reality (VR) as a low cost tool for the dissemination and communication of museum contents, cultural heritage, sites and evidences archaeological, has acquired a strategic, and sometimes necessary, role in the last ten years, such as highlighted by the latest literature (Kremers, 2020; Duguleană et al., 2018) and by the establishment or birth of dedicated journals (i.e.: International Journal of Virtual Reality; Digital Applications in Archaeology and Cultural Heritage; Virtual Archaeology Review).

The workflow developed by the research team for the study case of the San Menna church in Lucoli, which begins from geometric survey of the artefact to arrive at the use of contents structured through the Cardboard technology launched in 2014 by Google, integrating different low cost technologies, represents a process
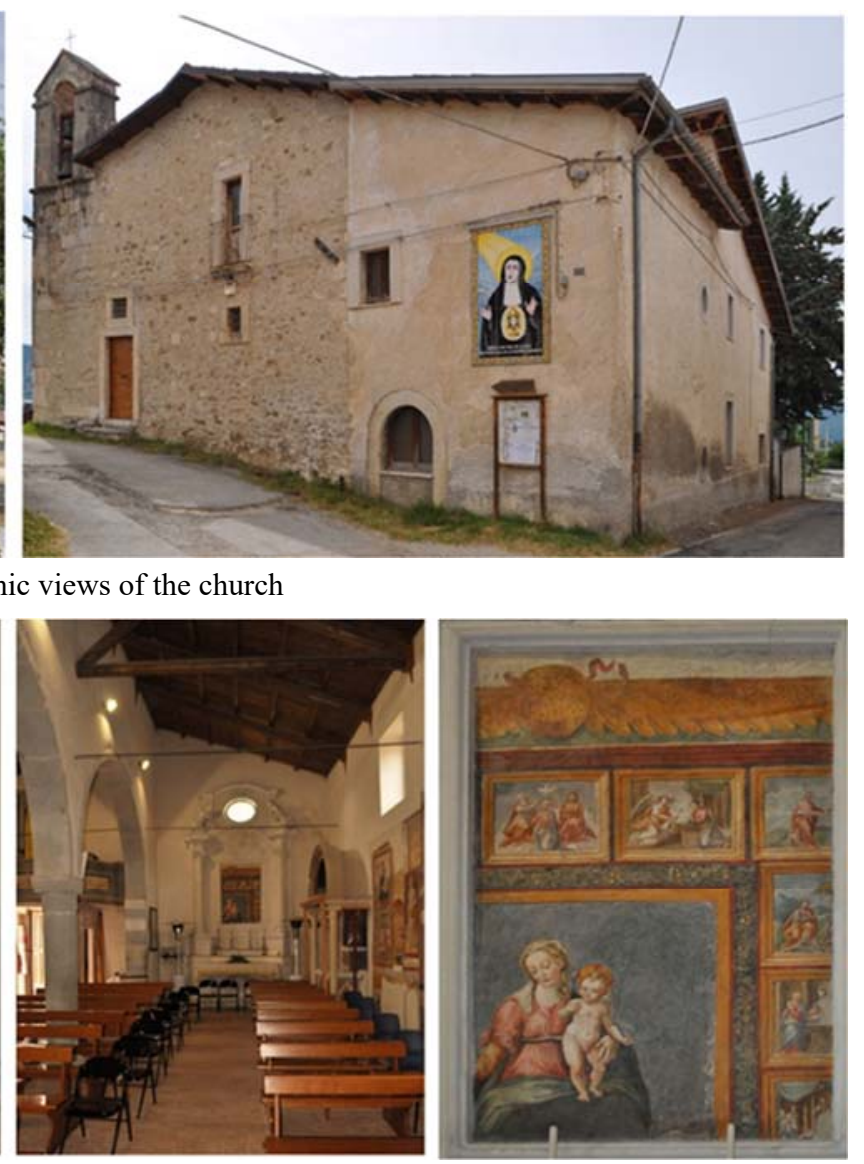

which a large Crucifixion whose protagonists are dressed according to fifteenth century style. Although the critics are still opposed, the fresco dates back to 1486, when the young Abruzzi artist Saturnino Gatti, already a skilled sculptor, became probably familiar with the painting art at the Sebastiano of Cola from Casentino's studio (Arbace, 2012).

In addition to the valuable fresco, a seventeenth century altar, artwork ascribed to Pompeo Cesura, another major exponent of Abruzzi culture and Raffaello Sanzio's follower (fig. 2), and currently visible from the central altarpiece. 


\subsection{Methodology and tools}

The first phase of the research concerned the in-depth knowledge of the artefact analysed in all its details through classic documentation tools, such as digital architectural survey, masonry analysis, iconographic system and conservation state of materials analyses, forms for the seismic vulnerability assessment of movable and artistic heritage.

The architectural survey was carried out with an integrated digital approach, combining laser scanning with the low cost techniques of Structure from Motion (SFM). This combining approach allows to obtain an objective result through the implementation of photorealistic textures (fig. 3) and generating of $360^{\circ}$ panoramas. In addition, the research of the publisher and archival sources has been integrated with the stratigraphic analysis of visible masonry carried out on the high-resolution photoplans extrapolated from the photogrammetric model and by the analysis of the degradation of the pictorial surfaces, also carried out on the same photoplans.
The information derived from scientific research has been collected in the virtual world, in order to create a valuable tool for management, conservation and accessibility of data useful not only for the enhancement but also for heritage education.

The interactive virtual tour, developed with the software 3D Vista Virtual Tour Pro that can be purchased with low cost, allow to use in the same virtual environment both of digital models both of technical information linked to the objects within the virtual tour through specific hotspots.

The virtual visit, in addition to its aim of enhancement and virtual accessibility of asset, is a very interesting and promising tool to manage and analyse efficiently and accurately the knowledge of artefact through controls that allow, thanks to the integration with the $2 \mathrm{D}$ images management software, to highlight the masonry identified with stratigraphic analysis, or the conservation state of frescoes. Similarly, it is possible to visualize for each artistic assets the main data collected by the SeVAMH protocol (fig.4).

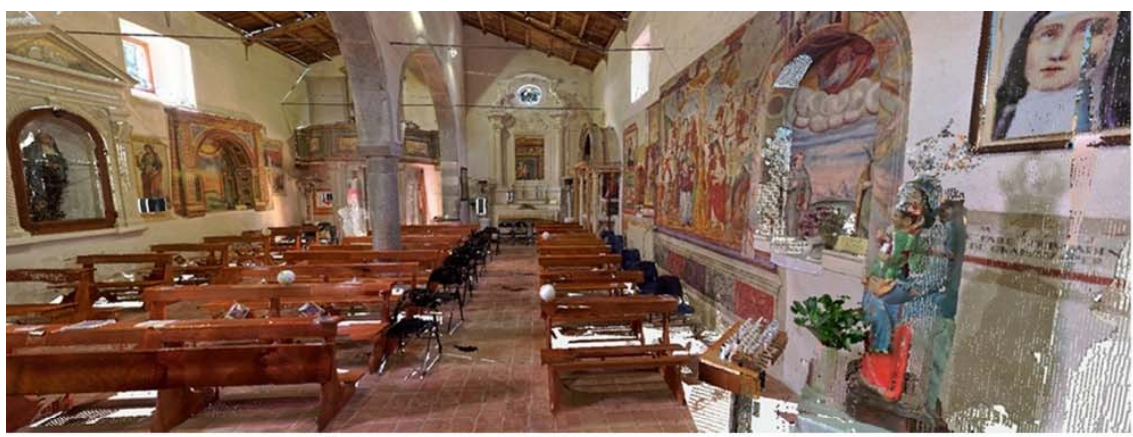

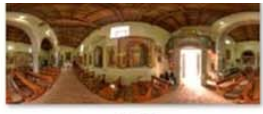

scan 4

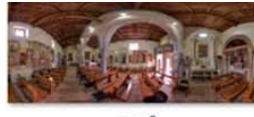

scans

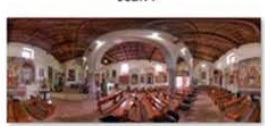

$\operatorname{scan} 6$

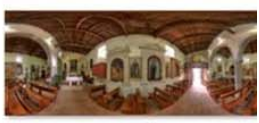

$\operatorname{scan} 7$

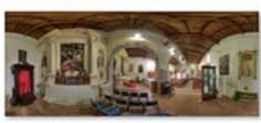

scan8

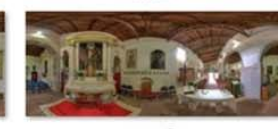

scan 9
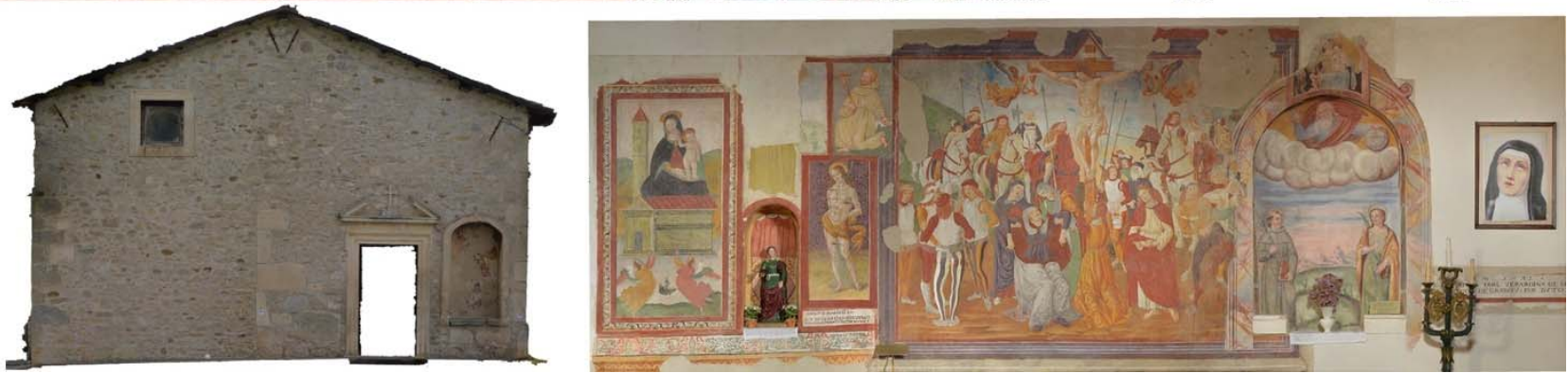

Figure 3. Point clouds and equirectangular images, top; orthophotoplans extrapolated from the textured photogrammetric model, bottom.

\section{SEVAMH ADD-ON FOR CONSERVATION OF} ARTISTIC ASSETS IN SEISMIC ENVIRONMENT

\subsection{SeVAMH protocol, basics}

The level of detail achieved by the architectural survey appears to be suitable to support also technical requirements for conservation and protection of the cultural heritage (Rainieri et al., 2015). The geometric characteristics of the structural and non-structural components are well reported and current conditions properly identified even remote operations (Marra et al., 2019). In particular, relevant data to be collected according to Italian Guidelines (Recommendations PCM, 2011) for the assessment of the so-called SLA (Artistic Limit State) of architectural and movable heritage can be collected (Borri, Corradi, 2019).

In the present case, the SeVAMH protocol (Marra, Fabbrocino, 2018) has been adopted. Figure 4 gives an overview of the forms collected in an electronic way that enables the operator to process and store, in a short time, relevant information on the conservation state of the different elements of the exposed artworks. The protocol also allows to obtain a clear knowledge about the mechanisms of seismic response and damage for each category of art objects detected. The correlation between quantitative data, defined through the artefact survey, and qualitative data, provided by the forms, allows to reach a knowledge framework able to support the identification of the most effective structural models to use for seismic vulnerability assessments of both the building as well as the movable property exposed in them, in a broad view of "container and content". In this way, it is possible to identify the most appropriate measures to mitigate their vulnerability of "container and content". At the same time, the results obtained from technologies and systems adopted highlight that these can be used as proper tools for the conservation and safeguarding of cultural heritage (Marra et al, 2019).

\subsection{Outcomes of the SeVAMH protocol implementation in the S. Menna Church}

In the present study case, the SeVAMH protocol has been applied to the valuable artworks of Abruzzo Renaissance housed in the 
artefact - the Virgin with Child fresco, ascribed to Pompeo Cesura, and the Crucifixion, ascribed to Saturnino Gatti - starting from the information directly collected from photogrammetric model.

The fresco ascribed to Pompeo Cesura is placed above the side altar to the main entrance and surrounded by a moulded stucco frame dating back to the 17 th century and, therefore, in baroque style. The fresco shows a good state of conservation, although in the central area some colour losses have been detected. The lack of degradation and alteration forms can be ascribed both to the different restauration works carried out between the 90s of the twenty century and the early years of twenty-first century, with the aim of reopening the church to worship since it was closed in the 1983 (Lico, 2001), and to the safety measure adopted after the 2009 seismic event.

The Crucifixion fresco ascribed to Saturnino Gatti is located on the left wall of the San Menna Church covering a large surface of the central area of the wall. The restoration works carried out
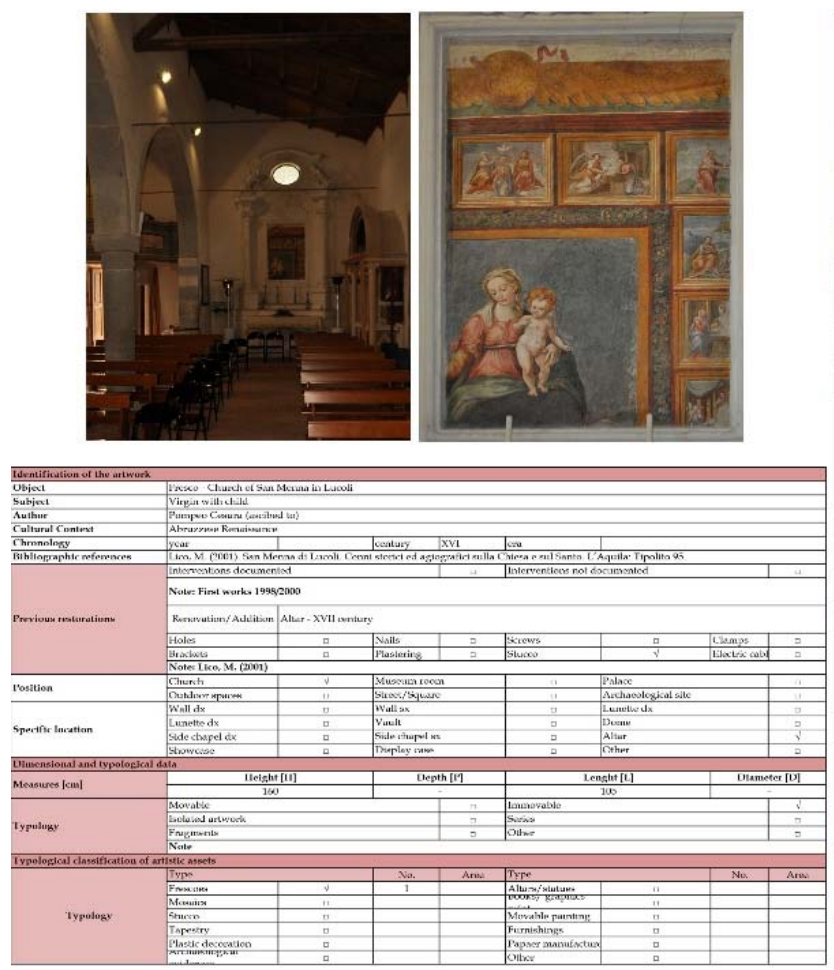

Figure 4. Example of expeditious documentation by SeVAMH survey form.

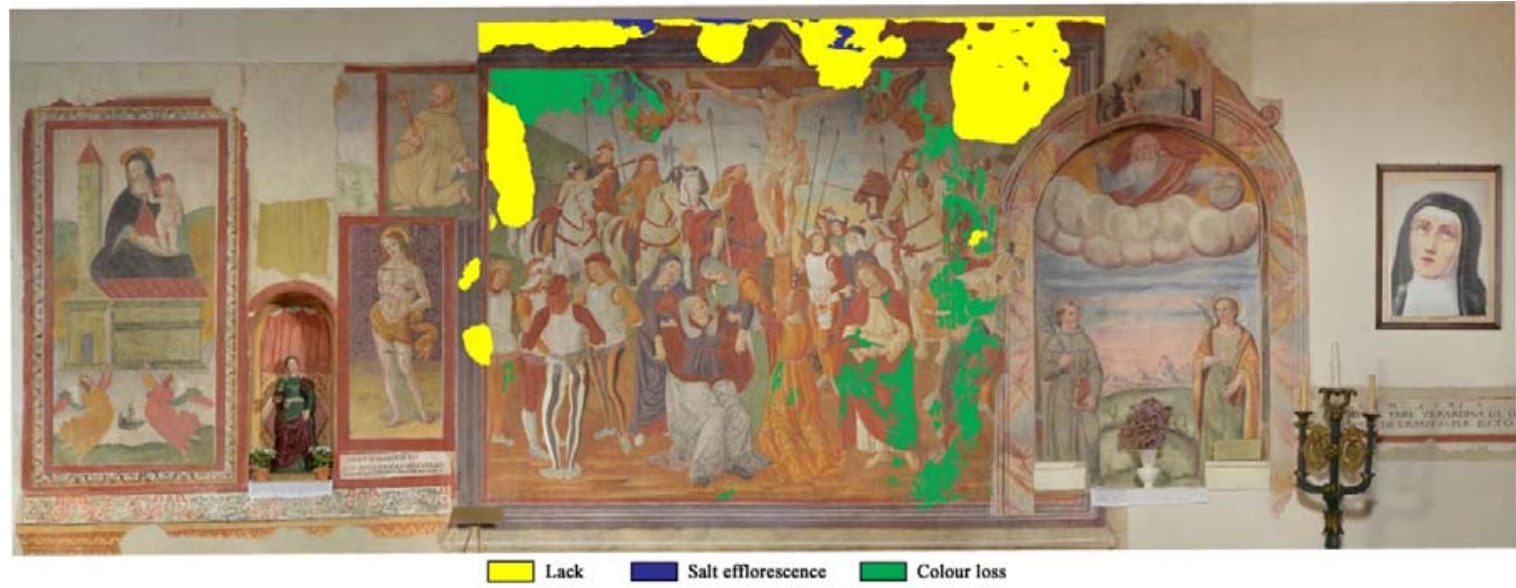

Figure 5. Degradation and alteration forms detected on the Crucifixion ascribed to Saturnino Gatti through SeVAMH protocol.

before the reopening of the church to the worship (1990-2001) can be clearly identified. Indeed, there are several achromatic reintegration of plaster lacks that, in some cases, could have been treated differently, i.e. using soft tone colours and simplifying the drawings in order to improve the reading of artwork as a whole. During the SeVAMH protocol compilation, the presence of efflorescences in the achromatic reintegration and the colour loss in the left part of the fresco has been detected (fig. 5). The occurrence of these degradation and alteration forms highlights the need to carry out specific investigation surveys, using nondestructive techniques such as the thermography. These alteration forms, indeed, are generally representative of humidity inside the masonry wall and, if not properly treated, could significantly damage the fresco and threat its preservation.

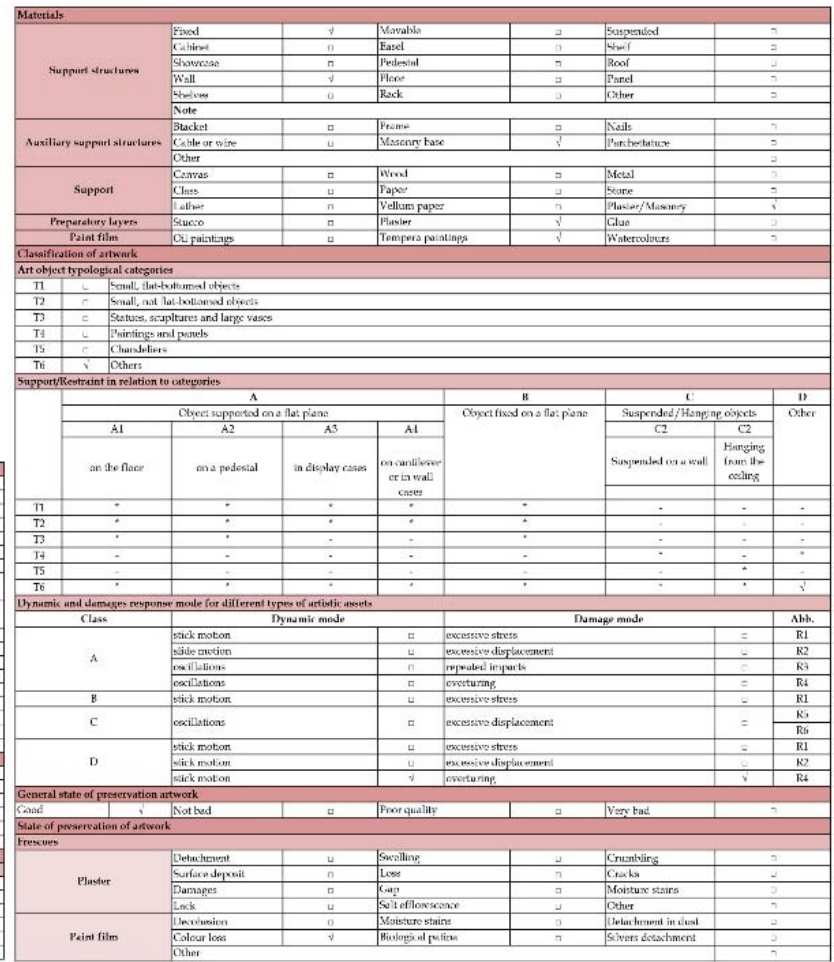

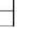$$
\text { . }
$$ 
As regards damages caused by seismic events, since these are frescoed surfaces that strongly interact with structural elements of building (masonry), it can be expected the masonry cracks, with successive fragmentation and loss of frescoed elements, or extreme and irreversible deformations.

The data collected and easily accessible from the artefact model developed in VR, provide useful information for seismic vulnerability assessment of cultural and listed heritage regard the SLA and, last but not least, the useful measures for structural modelling of the asset "container and content".

\section{VR TECHNOLOGY FOR THE DOCUMENTATION, ANALYSIS AND FRUITION OF CULTURAL HERITAGE}

The research carried out is aimed to demonstrate how the Virtual Reality (VR) of an artefact can became the representation of research results, facilitating the accessibility of the cultural heritage and contributing to its digital conservation. These aims have been pursued importing into the virtual environment the results obtained from archaeological analysis, those derived by the study of iconographic system and from the analysis of conservation state of movable and artistic assets also from seismic point of view. The choice to make the VR system through spherical images rather than through the photogrammetric model (previously tested in the L'Aquila area, cfr. Trizio et al., 2018) has arisen from the will to make the result available to a wide community because easily manageable through mobile devices that not always have high performance.

The virtual tour of the religious building is available in two modalities: desktop and immersive with VR box e virtual headsets.

Simultaneously several experiments have been carried out with the aim of connecting scientific data to digital models to increase the knowledge of cultural heritage thought its documentation.
It was decided to import digital models (point cloud and textured mesh) on the Sketchfab platform in the section devoted to cultural heritage because, in addition to being free and intuitive for users, it dialogues perfectly with the 3D Vista software used to create the tour virtual.

The first step was to select the $360^{\circ}$ spherical images produced for each laser scanner point of station (Faro focus S70) in order to be able to make visible both the interior and the exterior of the religious building. The selected equirerattangular projections have been modified with a $2 \mathrm{D}$ graphics program in order to improve the quality and correct the errors deriving from the automatic stitching caused by the laser scanner.

The $360^{\circ}$ panoramic images were imported into 3DVista software and linked to each other through an anchoring system that allow to move in a virtual tour (Fig.6).

The use of the virtual tour is possible thanks to the hosting service that the production company makes available with the purchase of the software free of charge for the first 3 months. A link allows to browse both with the PC and in immersive mode with the mobile devices combined with Cardboard and VR box, but also with more performing devices such as the Oculus Go that thanks to the internal browser access the hosting directly activating the tour with specially designed multimedia content (fig. 7).

Furthermore, the tour can be downloaded from the hosting to be used in offline mode. The tour was developed according to the guided exploration logic, therefore the user can visit the building thanks to a teleportation system that can be activated by selecting special hotspots (fig. 8). During the visit, it is possible to interact with the objects of the scenes activating the multimedia contents (audio, texts and images), some of these can be also downloaded, such as the data forms that can be acquired in pdf format (fig. 9).

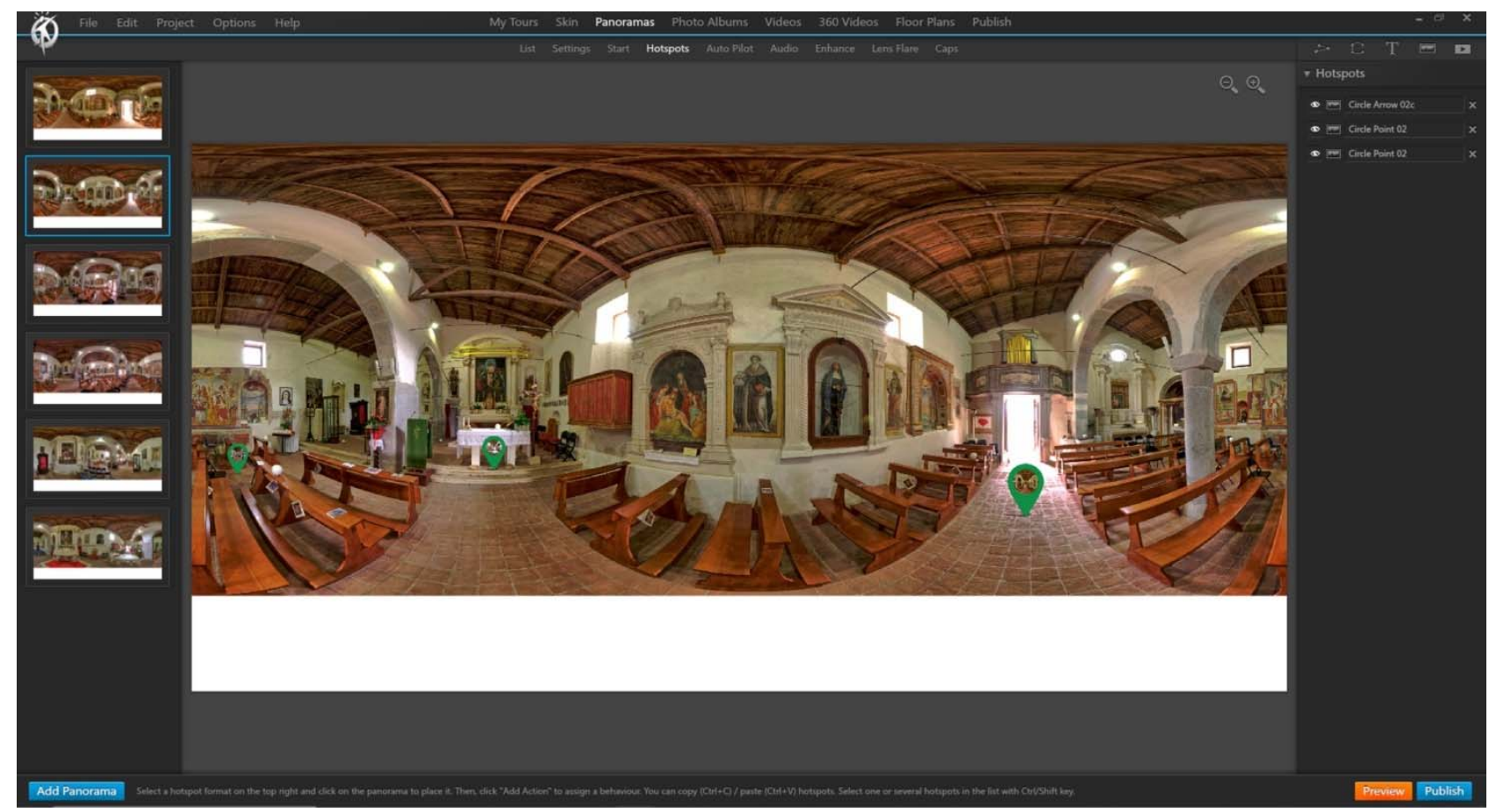

Figure 6. Screenshot of 3DVista software.

In desktop modality the user can view a menu with additional scientific and technical contents. Therefore, it is possible to access the results of the research: the architectural survey, the stratigraphic analysis of the walls, the iconographic analysis, the analysis on the conservation state, etc. One of the menu items allows to view digital models, both the point cloud and the photogrammetric model with photorealistic plots, transformed into semantic models thanks to the addition of contents. 
Instead, the immersive tour was designed for a tourist fruition of the church with the possibility of exploring it and hearing a narrative voice that, like a true tourist guide, explains the building history and the artworks inside it. Furthermore, some technical information has been added and reassumed by the data sheets, which have been inserted into hotspots manually activated by the user. This step has made it possible to solve the problem of consulting the forms that are difficult to read in immersive modality.

In conclusion, the product resulting from multidisciplinary research becomes a useful tool, as well as to increase the accessibility to the cultural heritage and to the tourist offer, also for the management and exchange of data between the several professionals.
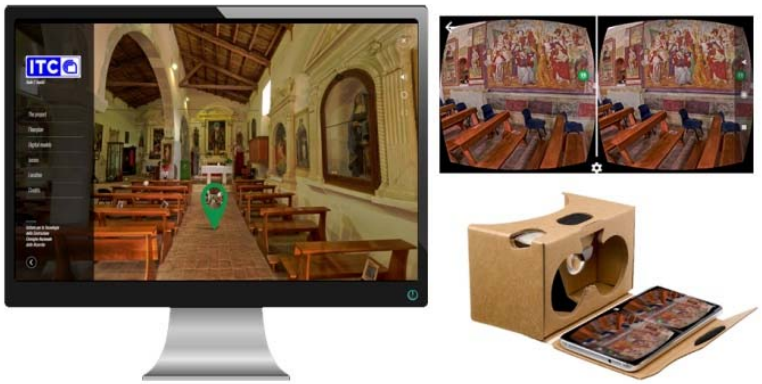

Figure 7. Different devices for the virtual tour.

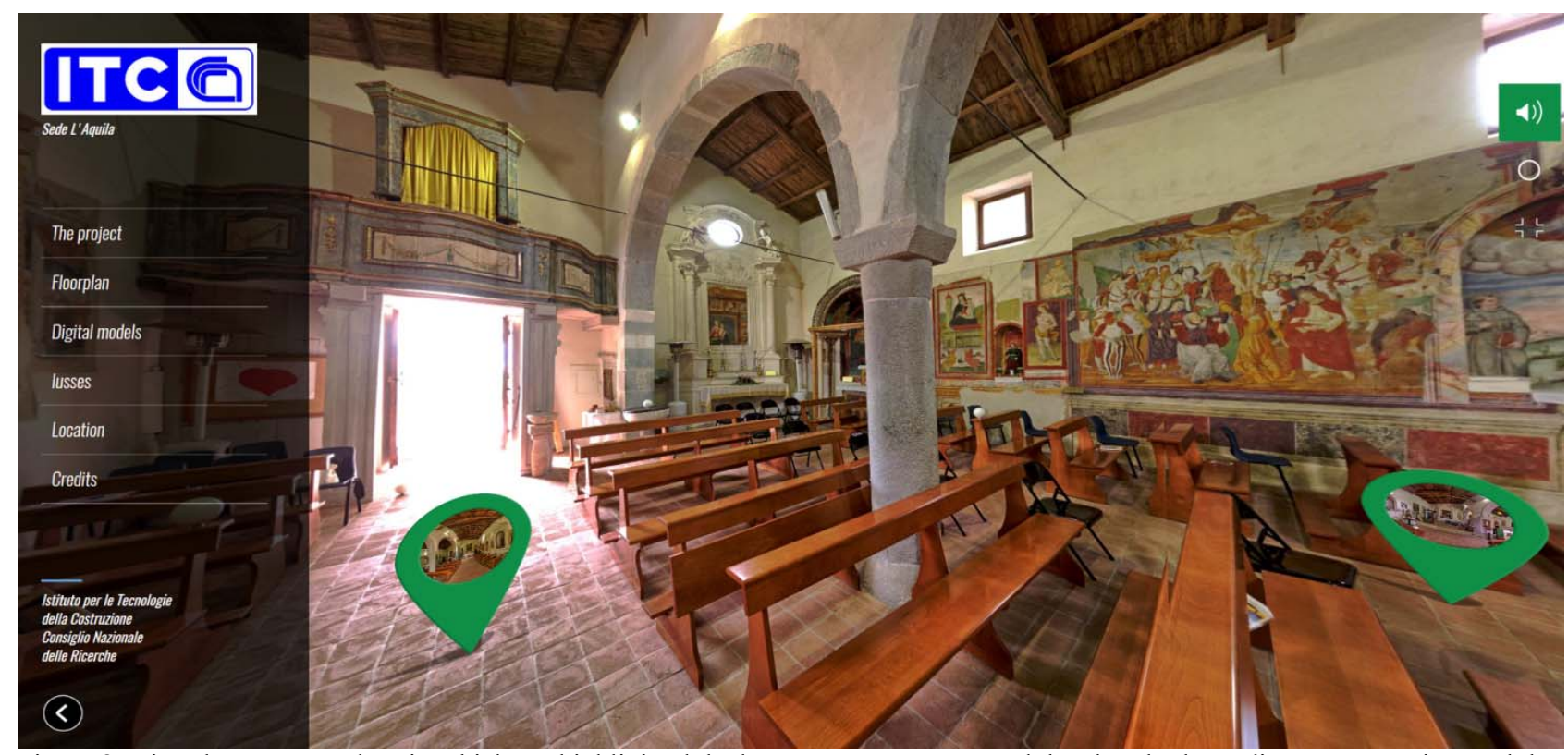

Figure 8. Virtual tour screenshot, in which are highlighted the hotspots, to move around the church, the audio content, active, and the menu

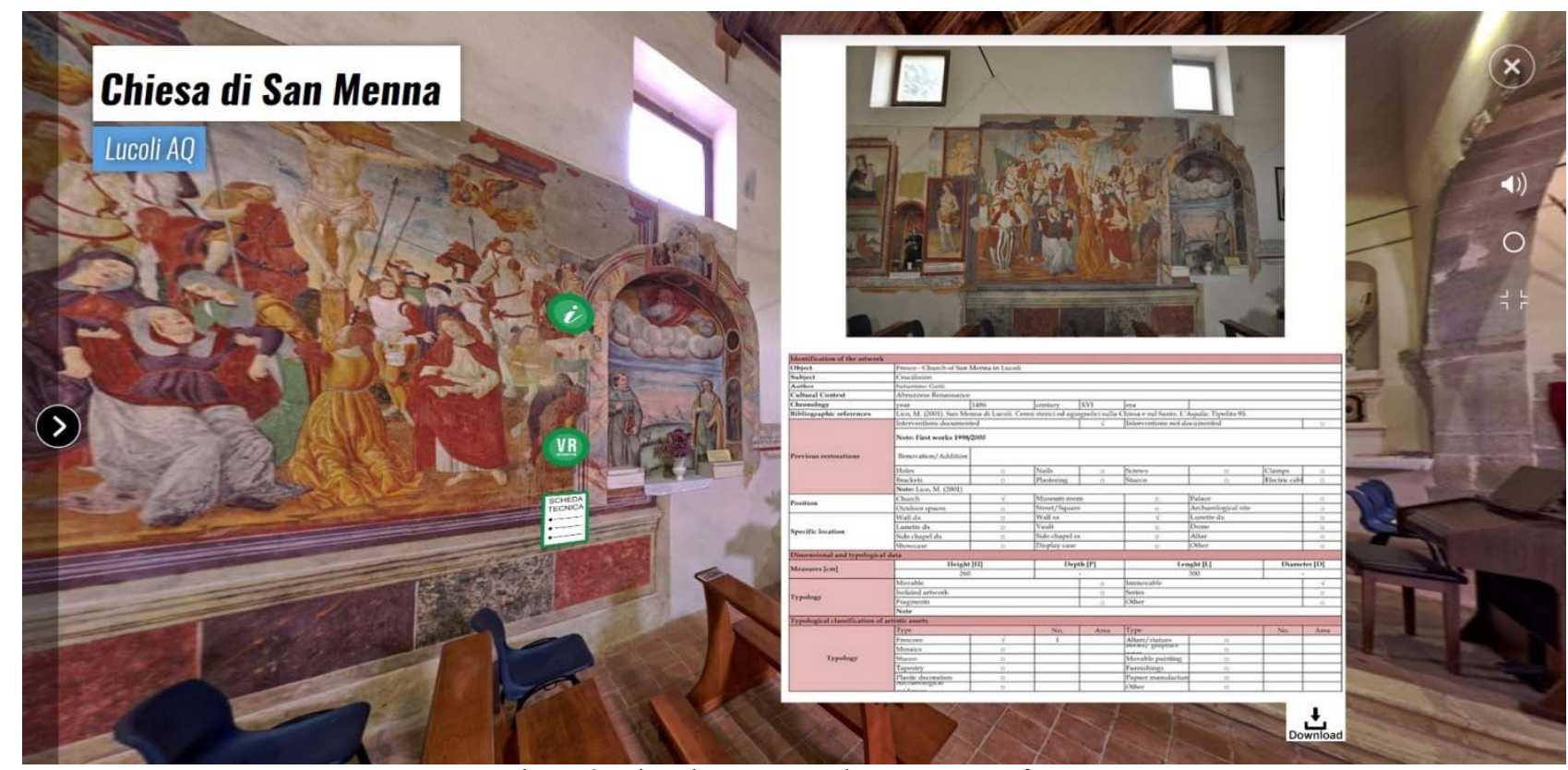

Figure 9. Virtual tour screenshot, SeVAMH form 


\section{CONCLUSIONS}

Among the main results of the research activities, in addition to the validation of the versatility of tools such as the digital photogrammetry software, there is the continuation of a research process that, since several years, with simple tools and minimum resources has the aim to document, assess and make accessible architectural assets, often inaccessible and exposed to relevant risks, among which is distinguished the seismic one. On the other hand, the results obtained from SeVAMH protocol for the knowledge of artistic assets are of great interest. The comparative analysis between the results obtained from the virtual visits of architectural complex and from traditional in field survey has not highlighted specific issues and has provided interesting information about the possibility to implement the procedure to other architectural contexts.

One of the future aims is to increase the research with further thematic readings that improve the diagnostic analysis of the building, such as for example the thermographic investigation of both the walls and the paintings both of the damage survey. The results will always be linked to the virtual system already created which will be shared through the ITC-CNR institutional website of L'Aquila branch.

The team is carrying out research activities on the built religious heritage, located in the area of L'Aquila, with the aim of increasing knowledge through studies carried out in different disciplinary fields (history of art, archaeology, conservation, etc.). The results of the research will be put into a system that provides for the integration of the several types of documentation adopted on the basis of needs, with the aim of increasing access to scientific data and giving the possibility of visiting, even in a virtual way, some buildings that are not always usable.

\section{NOTE}

Although the authors conceived the paper jointly, section 2 has been written by Ilaria Trizio; section 3 by Adriana Marra; section 4 by Francesca Savini, sections 1 and 5 have been written by all authors. Furthermore, are credited to: Alessandro Giannangeli all the elaboration of the three-dimensional photogrammetric model; Andrea Ruggieri the creation and processing of laser scanner survey; Alessio Cordisco the support in the creation of the VR environment; Sandra Fiore the search for archival and bibliographic material for the study case; Giovanni Fabbrocino the supervision of the research project and the validation of the tools for the artworks survey for seismic Artistic Limit State (SLA) assessment in SeVAMH protocol.

\section{REFERENCES}

Arbace, L., 2012: Saturnino Gatti: i volti dell'anima. Vita e opere di un artista del Rinascimento. De Siena, Pescara.

Bettio, F., Pintus, R., Jaspe Villanueva, A., Merella, E., Marton, F., Gobbetti, E., 2015: Mont'e Scan: Effective Shape and Color Digitization of Cluttered 3D Artworks. Journal on Computing and Cultural Heritage, 8, doi: 10.1145/2644823

Borri, A., Corradi M., 2019: Architectural Heritage: A Discussion on Conservation and Safety. Heritage, 2(1), 631-647.

Bozzelli, G., Raia, A., Ricciardi, S., De Nino, M., Barile, N., Perrella, M., Tramontano, M., Pagano, A., Palombini, A., 2019: An integrated VR/AR framework for user-centric interactive experience of cultural heritage: The Arkae Vision project. Digital
Applications in Archaeology and Cultural Heritage, 15, December 2019, e00124.

Duguleană, M., Carrozzino, M., Gams, M., Tanea, I. (eds.), 2018: VR Technologies in Cultural Heritage. First International Conference, VRTCH 2018 Brasov, Romania, May 29-30, 2018. Springer, Cham.

Fabbrocino, G., Marra, A., 2018: Strumenti di rilievo e caratterizzazione dei beni museali e artistici. In G. Fabbrocino and M. Savorra (eds.). La Certosa di Trisulti (pp. 200-219). Silvana Editoriale, Milano.

Kremers H. (ed), 2020: Digital Cultural Heritage. Springer, Cham.

Lico, M., 2001: San Menna di Lucoli. Cenni storici ed agiografici sulla Chiesa e sul Santo. Tipolito 95, L’Aquila.

Maiellaro, N., Varasano, A., Capotorto, S., 2018: Digital Data, Virtual Tours, and 3D Models Integration Using an Open-Source Platform. In M. Duguleană, M. Carrozzino, M. Gams and I. Tanea (eds.), VR Technologies in Cultural Heritage. First International Conference, VRTCH 2018 Brasov, Romania, May 29-30, 2018 (pp.148-164). Springer, Cham.

Marra, A., 2017: Il complesso monumentale di Santa Chiara a Napoli: un modello innovativo per la conoscenza e la valorizzazione. In O. Niglio and C. Visentin (eds.), Conoscere, conservare, valorizzare. Il patrimonio religioso culturale (Vol. III, pp. 141-146). Aracne Editrice, Roma.

Marra, A., Sabino, A., Bartolomucci, C., Trizio, I., Mannella, A., Fabbrocino, G., 2019: On a Rational and Interdisciplinary Framework for the Safety and Conservation of Historical Centres in Abruzzo Region. Journal of Architectural Heritage, 1-19, https://doi.org/10.1080/15583058.2019.1637478.

MiBAC, 2019: Ministry of Cultural Heritage and Activities General Direction of Museums. Three-year Plan for the Digitalisation and Innovation of Museums. http://musei.beniculturali.it(29 October2019) (in Italian).

Placidi, V., 1986: Strutture urbane e tipologie architettoniche: $i$ centri minori dell'alta e media Valle dell'Aterno. Marcello Ferri Editore, L'Aquila.

Rahamana, H., Champion, E., Bekele, M., 2019: From photo to 3D to mixed reality: A complete workflow for cultural heritage visualisation and experience. Digital Applications in Archaeology and Cultural Heritage, 13, June 2019, e00102.

Rainieri, C., Marra, A., Rainieri, G.M., Gargaro, D., Pepe, M., Fabbrocino, G., 2015: Integrated non-destructive assessment of relevant structural elements of an Italian heritage site: the Carthusian monastery of Trisulti. Journal of Physics: Conference Series, 628(1), doi:10.1088/1742-6596/628/1/012018.

Recommendations PCM, 2011: Directive of the Prime Minister, 09/02/2011. Guidelines for the assessment and the mitigation of seismic risk of cultural heritage with reference to Italian NTC2008. G.U. n. 24, 29/01/2011, Roma (in Italian).

Trizio, I., Marchetti, A., Redi, F., Savini, F., Giannangeli A., 2017: La chiesa di San Cipriano a Castelvecchio Calvisio (AQ) 
nella Baronia di Carapelle: documentazione speditiva e analisi stratigrafica 3D del manufatto. Archeologia dell'Architettura, XXII, 239-253.

Trizio, I., Savini, F., De Gasperis, G., Cordisco, A., 2018: Lost and inaccessible sites: the Heritage Interpretation through applications of VR. In R. Salerno (ed.). Drawing as (in) tangible representation. Atti del $40^{\circ}$ Convegno Internazionale dei docenti delle discipline della rappresentazione, XV Congresso UID Milano 13-15 settembre 2018(pp. 831-836). Gangemi Editore, Roma.

Trizio, I., Brusaporci, S., Luigini, A., Ruggieri, A., Basso, A., Maiezza, P., Tata, A., Giannangeli, A., 2019a: Experiencing the inaccessible. A framework for Virtual Interpretation and Visualization of remote, risky or restricted access Heritage Places. Int. Arch. Photogramm. Remote Sens. Spatial Inf. Sci., XLII-2/W15, 1171-1178, https://doi.org/10.5194/isprs-archivesXLII-2-W15-1171-2019, 2019.

Trizio, I., Savini, F., De Gasperis, G., Cordisco, A., Fiore, S.,2019b: La navigazione VR di un'opera d'arte per la narrazione di una fabbrica storica/ VR navigation of a work of art for the tale of a historical building. In P. Belardi (ed.), Riflessioni. L'arte del disegno/Il disegno dell'arte. Reflections. The art of drawing/ The drawing of art. Atti del $41^{\circ}$ Convegno Internazionale dei docenti delle discipline della rappresentazione, XVI Congresso UID, Settembre 2019 (pp.1767-1774). Gangemi Editore, Roma. 